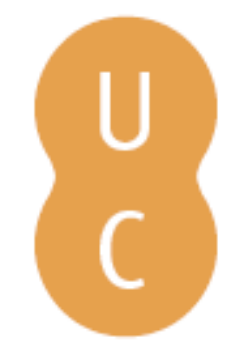

\title{
pommalina
}

\section{Do compasso ao computador: o mesmo desafio humanizador para o ensino e aprendizagem em matemática}

Autor(es): $\quad$ Nascimento, Eimard Gomes Antunes do; Sousa, Cristiane de

Publicado por: Imprensa da Universidade de Coimbra

URL

persistente: URI:http://hdl.handle.net/10316.2/41315

DOI: $\quad$ DOI:https://doi.org/10.14195/978 98926 1326-0_26

Accessed : $\quad$ 26-Apr-2023 14:04:25

A navegação consulta e descarregamento dos títulos inseridos nas Bibliotecas Digitais UC Digitalis, UC Pombalina e UC Impactum, pressupõem a aceitação plena e sem reservas dos Termos e Condições de Uso destas Bibliotecas Digitais, disponíveis em https://digitalis.uc.pt/pt-pt/termos.

Conforme exposto nos referidos Termos e Condições de Uso, o descarregamento de títulos de acesso restrito requer uma licença válida de autorização devendo o utilizador aceder ao(s) documento(s) a partir de um endereço de IP da instituição detentora da supramencionada licença.

Ao utilizador é apenas permitido o descarregamento para uso pessoal, pelo que o emprego do(s) título(s) descarregado(s) para outro fim, designadamente comercial, carece de autorização do respetivo autor ou editor da obra.

Na medida em que todas as obras da UC Digitalis se encontram protegidas pelo Código do Direito de Autor e Direitos Conexos e demais legislação aplicável, toda a cópia, parcial ou total, deste documento, nos casos em que é legalmente admitida, deverá conter ou fazer-se acompanhar por este aviso.

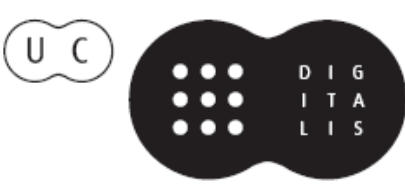




\title{
26. DO COMPASSO AOCOMPUTADOR: O MESMO DESAFIO HUMANIZADOR PARA O ENSINO E APRENDIZAGEM EM MATEMÁTICA
}

\author{
Eimard Gomes Antunes do Nascimento ${ }^{130}$ \\ Cristiane de Sousa ${ }^{131}$
}

\section{Resumo}

A abordagem deste tema tenciona promover uma reflexão frente à importância da utilização das Tecnologias de Informação e Comunicação (TIC) na educação, com o foco central no ensino da Matemática. A disseminação do computador e de todos os seus periféricos vêm provocando, nas últimas décadas, uma grande mudança social, sem deixar de incluir um impacto potencial do uso das novas tecnologias na área da educação. Porém, também importa evidenciar, alguns aspectos de desvantagens/ desafios que as mesmas ainda enfrentam no processo do ensino e da aprendizagem no âmbito escolar. Nesse sentido, buscou-se averiguar junto à literatura, alguns conteúdos que abordassem o assunto. O estudo faz uma breve história desde a evolução

130 Doutorando na Universidade de Aveiro - Portugal, em Educação no ramo da Didática e Tecnologia Educativa. Pesquisador bolsista da CAPES-Brasil-Proc. ${ }^{\circ}$ 9580/13-1. eimard@gmail.com

131 Doutorando na Universidade de Aveiro - Portugal, em Educação no ramo de Diversidade e Educação Especial. cristiane.sousa@ua.pt 
industrial, com as ideias de John Dewey e, na atualidade, com as ideias e pensamentos de duas personalidades importantes, como Papert (considerado o pai da informática na educação) e Freire (considerado o pai da educação inclusiva e humanizadora) num diálogo pertinente e interessante. A utilização das TIC, no contexto escolar, significa desenvolver vários sentidos nos alunos, fazendo com que criem novas formas de visualização, de aprimoramento dos conteúdos e, de partilha dos conhecimentos por intermédio do computador, de uma forma interdisciplinar, dinâmica e humanizadora. Contudo, na educação, não há uma tecnologia específica a ser utilizada, nem uma forma única de utilização destes recursos, mas um leque de oportunidades educativas que as diferentes tecnologias revelam, cabendo ao professor adequá-las às necessidades e especificidades da escola, pela qual é necessária a formação continuada ao professor quanto às possibilidades de uso da tecnologia.

\section{Abstract}

This text aims to promote reflection on the importance of the use of Information and Communication Technologies (ICT) in education, focusing the teaching of Mathematics. The widespread use of computers and all its components has been causing, in recent decades, a great social change, considering yet the impact of the use of new technologies in education. Nevertheless, it is also important to highlight some disadvantages/challenges that technologies still face in the process of teaching and learning in schools. Thus, this study analyzed, in literature, some contents about this subject. Within this aim, the text stress a brief history since the industrial revolution, considering John Dewey ideas and, recently, the ideas of two important personalities, Papert 
(considered the precursor of the informatics in education), and Freire (considered the precursor of the humanizing and inclusive education), in a relevant and interesting dialogue. The use of ICT in the school context fosters the development of students, enabling new ways of display the content and share knowledge through the computer, what leads to an interdisciplinary, dynamic and humanizing education. However, in education there is not a specific technology to be used, nor a specific way to use the resources, but a range of educational opportunities opened by different technologies. Hence, teachers may adapt them to the specific needs of each school, what makes necessary a continuous teacher education about the possibilities of the use of technology in classrooms. 


\section{Introdução}

A sociedade atual está sendo marcada por uma sucessão de transformações em vários setores, principalmente no que diz respeito ao desenvolvimento das tecnologias da informação, que vem ocorrendo de forma cada vez mais rápida. Vivemos numa sociedade cada vez mais automatizada, as máquinas foram introduzidas na revoluçao industrial e já fazem parte do nosso dia a dia, onde fica difícil imaginar uma atividade da vida moderna que não seja de alguma forma, mediada por uma máquina ou computador (Valente, 1998; Nascimento, 2012).

A disseminação do computador e de todos seus periféricos estão provocando uma grande mudança social. O impacto dessas novas tecnologias tem provocado mudanças também na educação. A escola, como instituição social responsável pelos processos formais de aprendizagem e construção de conhecimentos, não poderia assumir um papel neutro neste contexto chamado sóciotecnológico em que vivemos.

Atualmente é quase certo, quando falamos em educação, citar o uso das novas Tecnologias de Informação e Comunicação (TIC) na valorização e na melhoria do ensino e da aprendizagem, considerando que estas têm tido sua inserção demandada pelas práticas pedagógicas tornando-se cada vez mais necessárias as discussões e reflexões acerca dessa inclusão. A necessidade de diversificar métodos de ensino para contrariar o insucesso escolar ajudou ao uso crescente do computador no ensino (Fiolhais \& Trindade, 2003).

Em nosso tempo de globalização, e nas mudanças tecnológicas devido ao seu rápido avanço, e com consequência, cada vez mais cedo as crianças estão em contato com as tecnologias, fazendo com que os profissionais da educação se posicionem mais rapidamente a respeito de seu uso (Valente, 1999; Freire, 2005; Nascimento, 2013). Já que a inclusão digital tem-se colocado como um recurso 
a serviço do sistema educativo e, consequentemente, como parte do processo de ensino e da aprendizagem uma vez que faz constantemente a mediação entre indivíduo e conhecimento.

Diante desse fato justifica-se a realização desta pesquisa visando à utilização das TIC como ferramenta pedagógica no ensino da Matemática. Este trabalho foi realizado com respaldo em pesquisa bibliográfica, por meio da qual se buscou informações em livros, artigos de periódicos e sites de bases de dados científicas na internet. Segundo Chizzotti (1991), a investigação que requer utilizar "a bibliografia quer indicar que o pesquisador pode encontrar uma farta documentação para desenvolver a própria pesquisa e resolver os problemas teóricos e práticos que essa exigir"(p. 127).

O presente estudo vem viabilizar no tocante da importância de uma humanização no ensino e nas práticas com o uso das TIC para auxiliar o ensino e aprendizagem em sala de aula de Matemática, pois, para Freire $(2000,2005)$ a tecnologia faz parte da nossa vida e do nosso trabalho, assim, não podemos 'fingir' que não podemos aprender, mais é também, imperioso conhecer a história da 'prática educacional'.

\section{Educação e informática}

$\mathrm{Na}$ educação, quando falamos a palavra teoria, relacionamos logo em seguida, como será a prática? Desta teoria ou conceito, como vamos usá-la na prática o que se aprendeu na teoria?. A preocupação com essa prática, se teve maior atenção na revolução industrial, em torno do século XVI, em que ocorreu a introdução das máquinas na sociedade e consequentemente mudando sua formação de modo dinâmico e brutal.

No que tange aos preceitos escolares faz-se necessário salientar um dos autores que mais marcou o desenvolvimento de um 
ambiente de ensino, onde a própria escola funcionasse como uma comunidade ativa de vida, refletindo o modelo da sociedade vigente, é o célebre filósofo e educador norte-americano John Dewey (1859-1952).

Suas ideias foram implantadas firmemente no solo da vida norte americana, estendendo-se por quase todo o mundo e até os dias de hoje, tem influenciado outros teóricos de várias partes do nosso planeta. E no Brasil "as idéias pedagógicas de John Dewey tiveram uma importante influência sobre a educação brasileira" (Souza \& Martineli, 2009, p.169), levando a consolidação de uma ideia de participação e cooperação, segundo a qual o professor motivava o aluno a pensar no problema, verificar as possbilidades e deduzir o resultado.

Corroborando com as Ideias de Dewey, Freire (2001), que se dedicou ao ensino de forma apaixonada, defende que os métodos educacionais devem também privilegiar o desenvolvimento das habilidades e técnicas matemáticas através da resolução de exercícios. Para o autor, uma boa educação começa quando o aluno descobre por si só a solução de problemas. Neste sentido, tem-se a ideia que a prática favorece o aluno e a memorização da teoria ou conceito juntamente com a prática de exercícios.

Em realação ao uso das TIC na educação Matemática, D’Ambrosio (1986) chama atenção para o fato de que, em situações diversas, o aluno se mostra mais confortável com o uso de tecnologias. Valente (1999) complementa o pensamento, relatando que os alunos ficam mais motivados pelo uso do computador e softwares do que somente com os professores, visto que, nos últimos tempos as crianças e jovens fazem uso da tecnologia virtual em jogos e brincadeiras que são dispostos no mesmo formato da tecnologia educativa.

De acordo com Nascimento (2013), Machín (2008), Fitas e Costas (2008) existe uma discussão muito grande sobre o que seria 
Informática Educativa (IE) ou Tecnologia Educativa (TE) e qual o papel do computador nas escolas. O objetivo da IE ou TE é utilizar o computador como recurso didático para as práticas pedagógicas nos diversos componentes curriculares, incentivando a descoberta tanto do aluno quanto do professor e preocupando-se com "quando", "por quê" e "como" usar a informática para que a mesma contribua efetivamente para a construção do conhecimento.

Assim, a Informática na Educação, vai muito além de ensinar o aluno sobre competências necessárias para utilizar o computador, procurando caminhos para a sua utilização como um recurso transformador no ambiente de aprendizagem, fazendo com que os alunos explorem alternativas de resolução de forma rápida, integrada e motivante, rompendo barreiras entre os diferentes conteúdos do currículo escolar.

\section{Uso das tecnologias como auxiliar na educação}

A informática na educação se faz presente na maioria das escolas hoje, tendo como propósito contribuir com a qualidade do ensino, pois se constitui em uma ferramenta, que, utilizada corretamente, pode levar-nos a resultados educativos progressivamente mais positivos (Guerrero \& Kalman, 2010; Albuquerque \& Costa, 2013). Na verdade o mesmo contributo que esperamos das áreas disciplinares, também pode advir das novas tecnologias, potenciando-as como auxiliar nos diferentes processos de desenvolvimento pessoal e profissional.

Os Parâmetros Curriculares Nacionais (PCN) para o Ensino Fundamental e Médio expressam a importância dos recursos tecnológicos para a educação com vistas à melhoria da qualidade do ensino aprendizagem. Destacam que a informática na educação "permite criar ambientes de aprendizagem que fazem sugerir novas formas de pensar e aprender" (Brasil/MEC/SEF Brasil, 1998a, p. 147). 
Além disso, ressaltam que o uso da tecnologia na educação não deve ser encarado apenas como uma inovação pedagógica para o uso de novos meios e instrumentos, sendo necessário saber que os diferentes recursos tecnológicos podem contribuir para a educação, identificando quando, porquê e como a tecnologia pode mediar e auxiliar os processos de ensino/aprendizagem.

Os PCN destacam que:

É necessária e suficiente a utilização da informática como disciplina na Educação Básica por que necessitam de conhecimentos em softwares para a vida no dia a dia. Com tanta modernidade tecnológica, sentimos a grande necessidade de inserir a informática no contexto educacional. (Brasil, 1998a, p. 67)

Não só na Educação Básica, mas também no Ensino Superior o computador deve ser usado como instrumento de trabalho (Freire, 2005), como destacam as diretrizes curriculares para o curso de Matemática,

[...] desde o início do curso o bacharelando deve adquirir familiaridade com o uso do computador como instrumento de trabalho, incentivando-se sua utilização para formulação e solução de problemas. [...] Desde o início do curso o licenciando deve adquirir familiaridade com o uso do computador como instrumento de trabalho, incentivando-se sua utilização para o ensino de matemática, em especial para a formulação e solução de problemas. É importante também a familiarização do licenciando, ao longo do curso, com outras tecnologias que possam contribuir para o ensino de Matemática [...] (Brasil, 1998b, pp. 5-6).

A utilização das TIC no contexto escola significa desenvolver vários sentidos nos alunos, fazendo com que criem novas formas 
de visualização, de aprimoramento dos conteúdos das disciplinas curriculares e de partilha dos conhecimentos por intermédio do computador, de uma forma interdisciplinar e dinâmica.

Desta forma, o computador mediante os softwares educativos utilizados como ferramentas auxiliares podem se tornar um instrumento de estímulo aos alunos e um desafio aos professores, pois contribui para o desenvolvimento da prática docente. Valente (1998), que destaca a ideia da necessidade de uma educação para a compreensão, de qualidade e interativa, assim se expressa:

[...] a solução para uma educação que prioriza a compreensão é o uso de objetos e atividades estimulantes para que o aluno possa estar envolvido com o que faz. Tais alunos e objetos devem ser ricos em oportunidades, que permitam ao aluno explorá-las e, ainda, possibilitar aberturas para o professor desafiar o aluno e, com isso, incrementar a qualidade da interação com o que está sendo feito (Valente, 1998, p. 90).

Em geral, a utilização das TIC no ensino revela-se inegavelmente positiva não apenas por ele ser um instrumento que é hoje imprescindivel a um ensino ativo, baseado na descoberta progressiva do conhecimento pelo aluno e na maior autonomia da sua aprendizagem, mas também porque, levantando novas questões e ressuscitando algumas questões antigas, relança a discussão em torno de assuntos cruciais como as relações professor-aluno, aluno-aluno e o desenvolvimento das capacidades cognitivas do professor e do aluno (Fiolhais \& Trindade, 2003).

Sabe-se que o sucesso educacional não se concentra apenas nas ferramentas metodológicas utilizadas, mas em especial na presença do professor, que está constantemente procurando meios para melhorar a qualidade do ensino. Neste sentido, a tecnologia da informática possibilita um novo caminho a ser percorrido. 


\section{A matemática e a modelagem do dia-a-dia vivido}

Quando um professor aplica em sala de aula a modelagem como estratégia de ensino, ele tem a intenção de ensinar matemática e de explorar as aplicações matemáticas no dia-a-dia (Jacobini \& Wodewotzki, 2006). Nesta construção de modelo e da interação entre a matemática utilizada na modelagem e o conteúdo programático, o professor mostra aos alunos a oportunidade de conviver com conteúdos vivos, práticos, úteis e significativos.

Entretanto, vemos essa ação de ensinar e de aprender como sendo apenas uma das possibilidades oferecidas pela modelagem Matemática. Ao restringir a ela suas pretensões pedagógicas, o professor mantém seu olhar exclusivamente na matemática e deixa de considerar outras oportunidades tanto para o crescimento intelectual e cognitivo dos alunos como para a sua formação crítica (Jacobini \& Wodewotzki, 2006). Dentre essas oportunidades necessita-se de ações sociais e políticas possibilitando trabalhos investigativos inerentes à aplicação da modelagem no currículo escolar, com a expectativa de que despontem, em todos os participantes, quer novos olhares e novos saberes sobre a matemática e os fatos investigados, quer sobre a realidade social que se encontra ao seu redor (Freire, 2005; Valente, 1999).

\section{Freire e os matemáticos: um diálogo interdiciplinar}

Num vídeo memorável, podemos testemunhar o encontro entre dois ícones da pedagogia moderna, Paulo Freire, defensor da educação pelo diálogo e da aproximação interpessoal do professor e alunos e do educador Matemático Seymour Papert, defensor da utilização dos computadores em sala de aula, como ferramenta de aprendizagem e contributo para uma educação experimental 
e espontânea (Freire \& Papert, 1995), ambos discutindo sobre o futuro da escola e o impacto dos novos meios de comunicação no modelo de escola atual.

Freire relata neste encontro, que defende uma pedagogia da curiosidade, uma pedagogia da pergunta, que é exatamente a pedagogia que se funda nessa curiosidade, sem a qual não há pedagogia capaz de motivar a criança, ou o aluno, a participar e a interrelacionar e, assim, obter uma aproximação interpessoal com os colegas e com o professor. Segundo Parpert (Freire \& Papert, 1995), fora da escola, isto é, na vida real, existe um desequilíbrio entre o aprendizado e o ensino que está muito mais valorizado socialmente que o aprendizado. Na verdade, tarefa da escola e dos educadores seria a de dar valor ao aprendizado, aos custos do ensino. Ainda para o mesmo autor "nada é mais ridículo do que a ideia de que a tecnologia possa ser usada para melhorar a escola" (Freire \& Papert, 1995, 14:35 minutos), sendo certo que na escola que conhecemos, esperamos que haja sempre lugares para as crianças se encontrarem com pessoas para aprender.

$\mathrm{Na}$ informática, as coisas normalmente acontecem mais rápido. Então o objetivo dos educadores deveria ser procurar novas maneiras de lidar com as crianças e de se relacionar dentro do triângulo: adulto, criança, saber. Precisamos de relacionamentos bem diferentes e é claro que isso não aconteceria de forma fácil e automática. Papert defende a pedagogia experimental, na qual o aluno deva vivenciar cada conteúdo que aprende; em que a tecnologia deve ser a ferramenta fundamental para o aprendizado e a escola ser um ambiente de encontro entre os alunos e dos alunos com o professor.

Contudo, as ideias propostas por Papert não têm ainda um acolhimento minimamente significativo nas escolas brasileiras e portuguesas, uma vez que a estrutura educacional e os objetivos da escola, estão submissas as políticas governamentais dos respectivos países, nem sempre colocando a educação e a pesquisa científica 
em um plano de interesse geral, remetendo-as, de forma continuada, para opções mais alinhadas com interesses dominantes, na unidade epocal hodierna. No que se refere às tecnologias aliadas à educação, ainda se encontram dando pequenos e lentos passos, pois dependem muito de resultados que os governos esperam das avaliações que vão realizando.

\section{Considerações finais}

A ideia dos pesquisadores sobre a prática ser um complemento da teoria se verifica durante o processo de evolução da sociedade. Assim, constatou-se que, pelo menos ao longo dos dois últimos séculos, ou mais precisamente, desde o início da revolução industrial, essa preocupação tem sido autocraticamente dominante.

$\mathrm{O}$ uso de computadores em ambientes educativos pode ajudar-nos a relançar as bases da relação das pessoas com as aprendizagens e com a ação diária, cidadã ou profissional. Para isso, e em termos gerais, a utilização da Informática Educativa em uma escola implica desenvolver o conteúdo das disciplinas curriculares por intermédio do computador, progressivamente de uma forma interdisciplinar e integrada.

Este processo não depende somente dos recursos físicos, mas sim da conscientização por parte de toda a escola, incluindo o professor, as direções e os responsáveis políticos, para que eles possam ser mobilizados e desenvolvidos ao serviço de uma aprendizagem significativa.

Procuramos mostrar, nesta breve síntese, que a utilização das TIC, descritas com o objetivo de serem inseridas no processo de ensino, pode ser propícia ao desenvolvimento de uma aprendizagem mais significativa e problematizadora, evidenciando vantagens que proporcionam a realização de atividades mais desafiadoras, motivadoras, interessantes, dinâmicas e interativas. 
As TIC no contexto escolar podem se constituir como um caminho para o professor vivenciar com os alunos o processo de ensino e aprendizagem, revelando-se a satisfação, a motivação, a competência e a habilidade em relação aos objetivos preconizados pelo Plano de Desenvolvimento da Educação, com vistas ao desenvolvimento científico, tecnológico, social e cultural.

Verifica-se ainda, que o uso das TIC para auxiliar o processo de ensino e aprendizagem em sala de aula, pode contribuir para a compreensão dos conceitos e para sua colocação em prática, além do desenvolvimento de competências, como raciocínio lógico, dedução, entre outros.

Em se tratando da utilização de novas tecnologias no contexto educacional, o que se percebe é que o educador encontra-se inserido num emaranhado de conexões cujo centro é móvel, pois a mudança é frequente, esperada e, por vezes, extraordinária. Não há uma tecnologia específica a ser utilizada, nem uma forma única de utilização dos recursos tecnológicos, mas um leque de oportunidades educativas que as diferentes tecnologias revelam, cabendo ao professor adequá-las às necessidades e especificidades da escola e do alunado com que atua.

Entretanto, para que tais adaptações possam se efetivar, é necessário domínio do professor quanto às possibilidades de uso da tecnologia na educação. A formação do professor deve prover condições para que ele construa conhecimento sobre as técnicas computacionais, entenda por que e como integrar o computador na sua prática pedagógica e seja capaz de superar barreiras de ordem administrativa e pedagógica.

Finalmente, devem-se criar condições, como cursos de formações continuada para que o professor saiba re-contextualizar tanto o aprendizado como as experiências vividas durante a sua formação para a sua realidade de sala de aula compatibilizando as necessidades de seus alunos aos objetivos pedagógicos a que se propõe atingir. 


\section{Referências}

Albuquerque A. M. C. \& Costa R. R. R. (2013). Experienciando práticas educativas no laboratório de informática. In Encontro da Linha de Educação Currículo e Ensino da Universidade Federal do Ceará, 1, 307-311. Brasil: Imprece.

Chizzotti, A. (1991). A pesquisa em ciências humanas e sociais. São Paulo: Cortez.

D’ambrosio, U. .(1986). Da realidade à ação: reflexões sobre educação e matemática ( $2^{\mathrm{a}}$ ed.). Campinas: Editora da Universidade Estadual de Campinas.

Dewey, J. (1985). Vida e Obra. Coleção os Pensadores. (2a ed.). São Paulo: Abril Cultural.

Fiolhais, C., \& Trindade, J. (2003). Física no computador: o computador como uma ferramenta no ensino e na aprendizagem das ciências físicas. Revista Brasileira de Ensino de Física, 25(3), 259-272. doi:10.1590/S1806-11172003000300002

Fitas, E. S. \& Costa C. (2008). Quadros Interactivos: Relato de Investigações Realizadas no âmbito do Ensino e Aprendizagem da Matemática. Revista Tecnologia e Educação Matemática, 15, 221-243. Disponível em http://spiem.pt/DOCS/ ATAS_ENCONTROS/2008/2008_25_ESFitas.pdf

Freire, P. (2000). Educação e Mudança (12a ed). São Paulo: Paz e Terra.

Freire, P. (2001). Pedagogia da Autonomia: Saberes necessários à prática educativa (17 ed). São Paulo: Paz e Terra.

Freire, P. (2005). Pedagogia do Oprimido: Saberes necessários à prática educativa ( $47^{\mathrm{a}}$ ed). São Paulo: Paz e Terra.

Freire, P. \& Papert, S. (1995). O Futuro da escola e o impacto dos novos meios de comunicacao no modelo de escola atual. Vídeo produzidos por Márcia Moreno e Marco Aurélio Del Rosso. São Paulo: TV PUC de São Paulo com apoio do Jornal.

Guerrero, I. \& Kalman, J. (2010). La inserción de la tecnología en el aula:estabilidad y procesos instituyentes en la práctica docente. Revista Brasileira de Educação, 15(44), 213-229.

Jacobini, O. R., \& Wodewotzki, M. L. L. (2006). Uma reflexão sobre a modelagem matemática no contexto da educação matemática crítica. Bolema: Boletim de Educação Matemática, 19(25), 71-88. Disponível em http://www.scielo.br/pdf/ rbedu/v15n44/v15n44a02.pdf

Machín, M. C. (2008). CAS (Computer Algebra System) En La Enseñanza Y Aprendizage del Cálculo. Algunos Resultados de Investigación. Revista Caderno de Pesquisa, 111, 47-71.

Nascimento, E. G. A. (2012). Avaliação do software GeoGebra como instrumento psicopedagógico de ensino em geometria. (Dissertação de Mestrado, Faculdade de Educação, Universidade Federal do Ceará, Fortaleza). Recuperado de http:// www.repositorio.ufc.br/handle/riufc/3081

Nascimento, E. G. A (2013, Agosto,). A importância da informática educativa nas séries iniciais. In Santos, A. N., Gomes, S. L., Neto, J. A. G., \& Caldas, O.F. M., Filho (Orgs.) I Encontro da Linha de Educação Currículo e Ensino da Universidade Federal do Ceará. Anais Saberes da Docência, Currículo e Ensino (pp. 295-300). Fortaleza, Brasil: Imprece. 
Souza, R. A. \& Matineli T. A. P. (2009). Considerações Históricas sobre a Influência de John Dewey no Pensamento Pedagógico Brasileiro. Revista HISTEDBR on-line 35, 160-162. Campinas:São Paulo. Retirado de http://www.histedbr.fe.unicamp. br/revista/edicoes/35/art11_35.pdf

Valente, J. A.. (1998, Maio). Informática na educação: a prática e a formação do professor. In IX ENDIPE (Org.). II Anais I do IX Encontro Nacional de Didática e Prática de Ensino. Vol.1/2. Olhando a qualidade do ensino a partir da sala de aula (pp. 1-10). Águas de Lindóia/Universidade de São Paulo, Brasil: Editora Vozes.

Valente, J. A.. (1999). O computador na Sociedade do Conhecimento. Campinas: Unicamp/Nied.

\section{Legislação e documentos oficiais}

Brasil/MEC/SEF (1998a). Parâmetros Curriculares Nacionais: Terceiro e Quarto ciclos de Ensino Fundamental - introdução aos parâmetros curriculares nacionais, Matemática. Secretaria de Educação Fundamental, Brasília: MEC/SEF. Disponível em http://portal.mec.gov.br/seb/arquivos/pdf/ intro ducao.pdf.

Brasil/MEC/SEF (1998b). Parâmetros Curriculares Nacionais: Terceiro e Quarto ciclos de Ensino Fundamental. Matemática. Secretaria de Educação Fundamental, Brasília: MEC/SEF. Disponível em http://portal.mec.gov.br/ seb/arquivos/pdf/ matematica.pdf. 